\title{
The Significance of Hazardous Chemicals in Wastewater Treatment Works Effluents
}

\author{
Michael Gardner ${ }^{1}$, Sean Comber ${ }^{2}$, Mark D Scrimshaw ${ }^{3}$, Elise Cartmell ${ }^{4}$, John Lester ${ }^{4}$, Brian \\ Ellor $^{5}$ \\ ${ }^{1}$ Corresponding author, Atkins Limited, 500, Park Avenue, Aztec West, Almondsbury, Bristol BS32 \\ 4RZ, UK. Tel: +44(0)7834 506966 Fax: +44 1454 663333; email: michael.gardner@atkinsglobal.com \\ ${ }^{2}$ Plymouth University, Drake Circus, Plymouth, PL4 8AA, UK \\ ${ }^{3}$ Brunel University, Uxbridge, UB8 3PH, UK \\ ${ }^{4}$ Cranfield University, Cranfield, MK43 OAL, UK \\ ${ }^{5}$ UK Water Industry Research, 1 Queen Anne's Gate, London, SW1H 9BT, UK
}

\begin{abstract}
The advent of increasingly stringent and wider ranging European Union legislation relating to water and the environment has required regulators to assess compliance risk and to respond by formulating appropriate pollution control measures. To support this process the UK Water Industry has completed a national Chemicals Investigation Programme (CIP), to monitor over 160 wastewater treatment works (WwTWs) for 70 determinands. Final effluent concentrations of zinc, polynuclear aromatic hydrocarbons (fluoranthene, benzo(a)pyrene, benzo(b)fluoranthene, benzo(k)fluoranthene, benzo(g,h,i)perylene and indeno(1,2,3-cd)pyrene), "penta" congeners (BDEs) 47 and 99, tributyltin, triclosan, erythromycin, oxytetracycline, ibuprofen, propranolol, fluoxetine, diclofenac, 17 $\beta$-estradiol and 17a-ethinyl estradiol exceeded existing or proposed Environmental Quality Standards (EQSs) in over $50 \%$ of WwTWs. Dilution by receiving water might ensure compliance with EQSs for these chemicals, apart from the BDEs. However, in some cases there will be insufficient dilution to ensure compliance and additional management options may be required.
\end{abstract}

Key words - priority substance, regulation, wastewater, effluent, chemicals

\section{Introduction}

Recent European Union (EU) legislation in the field of water and the environment has extended the scope of pollution control measures required to protect surface waters (EC, 2000, 2008, 2012). This has been driven by the improved understanding of the environmental impact of hazardous chemicals contained in wastewater effluents upon receiving waters and the flora and fauna they support. These effects, particularly those associated with endocrine disruption (Sumpter, 2009), have received much attention in the last decade. Endocrine disruption in the aquatic environment was first reported by Dodds et al. (1938) and the impact of organic micropollutants and heavy metals have been known for number of years (Bedding et al. 1982; Lester et al. 1980) and have been the subject of legislation for an extensive period in the UK (Bedding et al. 1983; Lester, 1983). However, there has been a need within the EU to update and harmonize existing legislation (EC, 2000, 2008, 2012) including regulations to control of the introduction of more recently recognized hazardous chemicals (Behera et al. 2009; Gabriel et al. 2012; González et al. 2012; Martínez Bueno et al. 2012; Martin Ruel et al. 
2012; Rodil et al. 2012). European Union Directives including the Water Framework Directive (WFD) (EC, 2000) and the Priority Substances Daughter Directive (EC, 2008) have defined Environmental Quality Standards (EQSs) for substances that hitherto have not been subject to detailed scrutiny and control. Environmental Quality Standards, in the form of annual average and in some cases maximum admissible concentrations, have been set at EU level for over 30 substances. A further tranche of more than 20 standards for chemicals designated as 'specific pollutants' under Annex VIII of the WFD is under consultation at the UK national level. The wide range of chemicals involved (Bedding et al. 1982; Gonzalez et al. 2012; Kolpin et al. 2002) and the analytical difficulty of working at $\mathrm{ng} / \mathrm{L}$ levels (Buisson et al., 1984) in a complex matrix such as wastewater (Robertson and Lester, 1994) make this a challenging proposition. In order to address this, the UK water industry has initiated an ambitious programme of investigations the Chemicals Investigation Programme (CIP) which is coordinated by the UK Water Industry Research (UKWIR) organisation as part of the UK National Environment Programme. The CIP operates three phases:

- $\quad$ C1 - Investigations to assess risk from chemicals

Final effluents from 162 WwTWs from England, Scotland and Wales were collected and analysed to determine the concentrations of chemicals discharged to receiving waters and their compliance with identified quality criteria.

- $\quad$ C2 - Investigations to assess WwTWs performance Assessments of 28 WwTWs were completed to evaluate the treatment performance across primary, secondary and some tertiary treatment processes.

- $\quad$ C3 - Source investigations

Overall nine urban catchments across the UK have been studied to assess catchment sources of the CIP specified chemicals discharged to sewer.

This study reports the findings of the first phase (C1) and for further information on the additional CIP phases 2 and 3 see supplementary material. The objectives of phase 1 are:

- To identify chemicals of concern and their concentrations in final effluents;

- To assess the range of concentrations between treatment works in different areas and between works of different types;

- To evaluate the compliance risk posed by chemicals with respect to water quality standards;

- To determine an order of priority amongst chemicals for the possible implementation of control measures.

The work reported here provides a broadly representative picture of hazardous chemicals from WwTWs throughout the UK as illustrated in Figure 1. This will allow for the formulation of appropriate control measures, to meet limit values that are either new or which might be more stringent than before. 


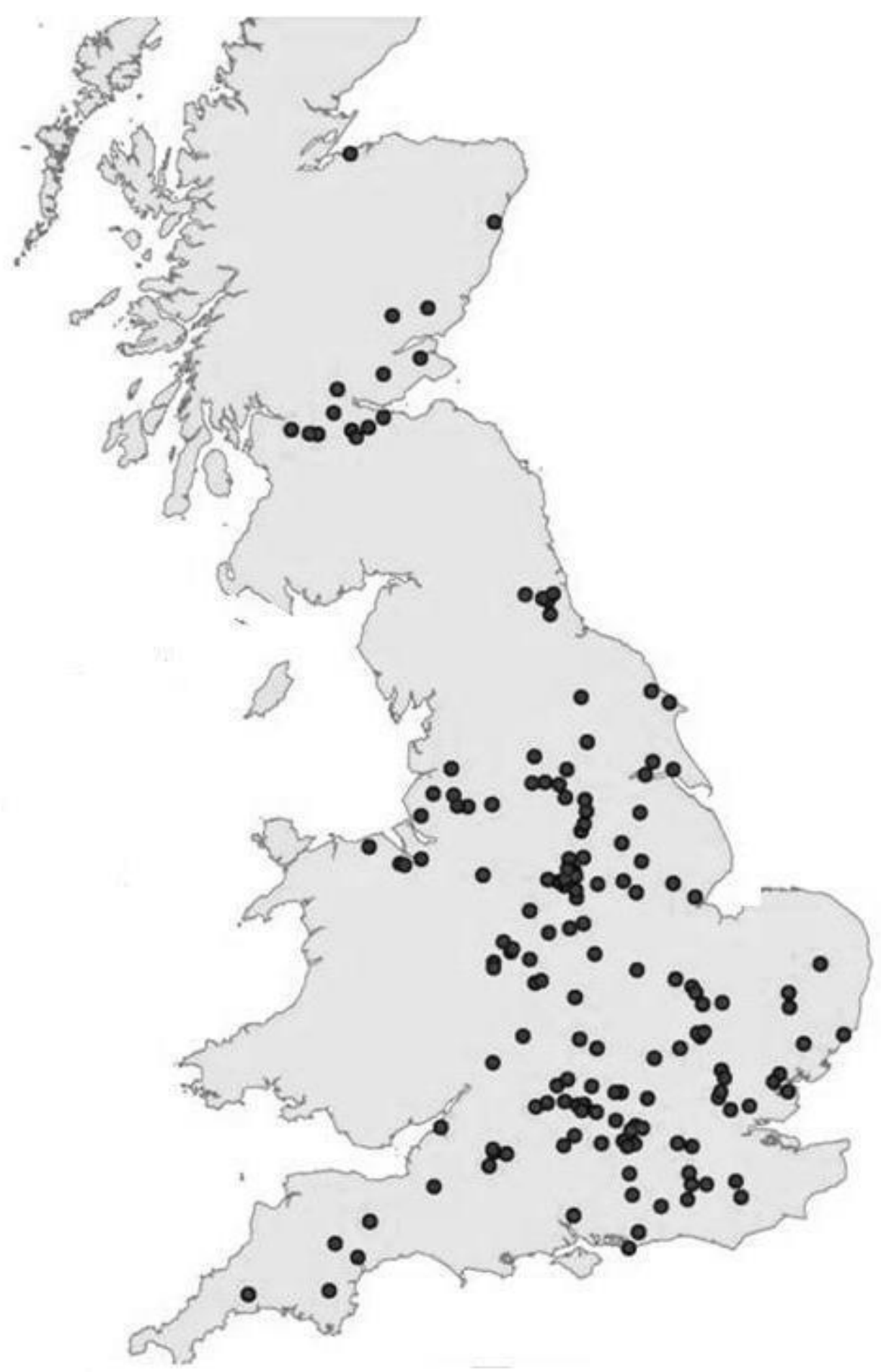

Figure 1. The locations of WwTW selected for phase 1 of the CIP for monitoring chemicals in final effluents.

\section{Materials and Methods}

\subsection{Design of the sampling programme}

Figure 2 shows the respective profiles of WwTWs chosen for the phase 1 final effluent investigations and those of all UK treatment works, illustrating, through the lightly shaded columns in the "all works" diagram, that the profile of WwTW sizes matched that of the total UK profile well, with $70 \%$ of the national population being served by works in the size range included in this part of the CIP 
programme. Of those excluded, the greater proportion of the population is served by a small number of extremely large WwTWs, with a population equivalent (PE) of $>500,000$ which were omitted from the programme because such sites tend to have known and specific industrial inputs that would have to be dealt with separately on a site by site basis. Inclusion of such works did not therefore accord with the aim of characterising the broader national picture. At the opposite end of the scale, the CIP does not provide a fully proportional representation of very small works (PE $<5,000)$. However, these works, although numerous, do not treat the wastewater from a large proportion of the population, are generally subject to larger dilution with receiving water (it might not be cost beneficial or feasible for some measures to be implemented at smaller works in any case). This therefore demonstrates that the selection of WwTWs was representative of UK WwTWs works in general, with the treatment processes operated at these WwTWs divided approximately equally between trickling filters and activated sludge based processes (supplementary Table 1).

\subsection{Sample collection}

Final effluents from 162 WwTWs were sampled either 14 or 28 times over a period of one year at each site. Works with lower dilution in receiving waters were sampled more frequently to increase confidence in site specific information. Grab samples were taken at different times during the day, with at least $15 \%$ of samples taken out of normal working hours (evenings or at weekends). Grab sampling was the chosen approach due to concerns over sample stability for stored composites. In addition, since compliance is usually assessed by means of grab sampling, knowledge about the variance of such samples was seen as of value in itself. Samples for the determination of metals were collected with polyethylene samplers, filtered $(0.45 \mu \mathrm{m})$ on site then acidified and stored in polyethylene (samples for mercury determinations were stored in glass or PTFE and preserved with acid dichromate (Feldman, 1974)). Samples for the determination of trace organic substances were collected with stainless steel samplers, stored in glass and transported at $4^{\circ} \mathrm{C}$ to the laboratories. Preservation with $3 \mathrm{ml}$ of $30 \%$ hydrochloric acid and $0.25 \mathrm{~g}$ of copper nitrate per litre was used for steroid estrogen samples. Storage for all organic samples was a maximum 5 days at $4{ }^{\circ} \mathrm{C}$.

\subsection{Analysis and quality control}

A test of sample stability in settled crude sewage and final effluents was undertaken (Gardner et al , 2012) to validate the sample storage period of 5 days under refrigeration, before the end of which it was specified that analysis must have been initiated. Additional spiked quality control samples were included to assess the impact of storage.

The programme covered more than 70 target chemicals, including 10 metals (total and dissolved), 22 EU Priority or Priority Hazardous Substances, 16 chemicals of emerging concern (herbicides, consumer chemicals and pharmaceuticals - see supplementary material) along with 16 supporting determinands including those that are measures of wastewater quality, treatment performance and the prediction of metal speciation. The required limits of detection (LODs) for the target chemicals were based on the EQS values in 2009 and are listed in Table 1. However, as of January 2012 further 

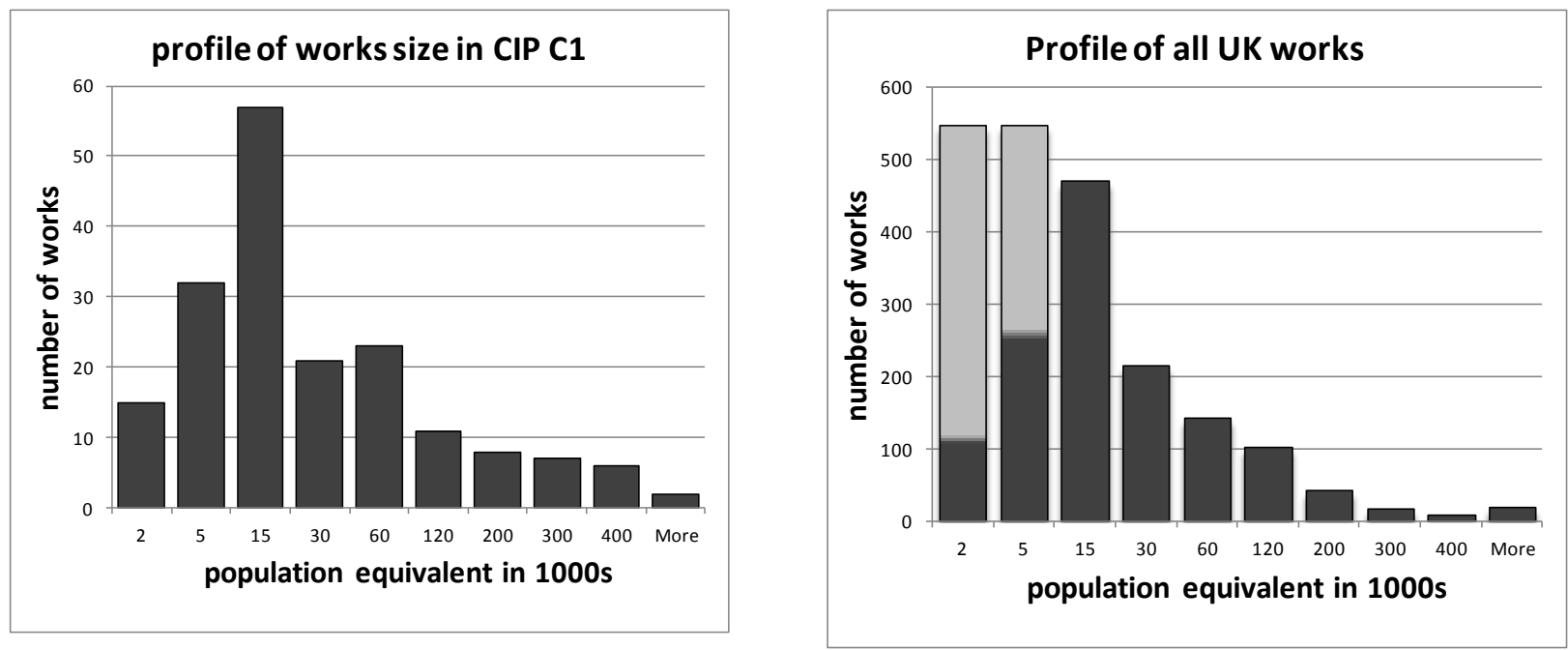

Figure 2

Comparison of population profiles of WwTWs included in the survey of chemicals in final effluents with all UK works. The grey shading illustrates that the study had a lower proportion of small works than are present nationally.

Table 1 Chemicals addressed in the Chemicals Investigation Programme

\begin{tabular}{|c|c|c|c|c|c|}
\hline $\begin{array}{l}\text { Field } \\
\text { Code }\end{array}$ & Substance & $\begin{array}{l}\text { Limit of } \\
\text { Detection } \\
\text { required } \\
\mu \mathrm{g} / \mathrm{l}\end{array}$ & $\begin{array}{l}\text { Field } \\
\text { Code }\end{array}$ & Substance & $\begin{array}{l}\text { Limit of } \\
\text { Detection } \\
\text { required } \\
\mu \mathrm{g} / \mathrm{l}\end{array}$ \\
\hline $\begin{array}{l}\text { NID } \\
\text { NIT }\end{array}$ & $\begin{array}{l}\text { nickel (dissolved) } \\
\text { nickel (total) }\end{array}$ & $\begin{array}{l}0.5 \\
0.5\end{array}$ & ANT & anthracene & 0.1 \\
\hline $\begin{array}{l}\text { NIT } \\
\text { PBD }\end{array}$ & $\begin{array}{l}\text { nickel (total) } \\
\text { lead (dissolved) }\end{array}$ & $\begin{array}{l}0.5 \\
0.2\end{array}$ & FLU & fluoranthene & 0.1 \\
\hline PBT & lead (total) & 0.2 & NAP & naphthalene & 2 \\
\hline CUD & copper (dissolved) & 0.3 & BAP & benzo(a)pyrene & 0.05 \\
\hline CUT & copper (total) & 0.3 & BBF & benzo(b)fluoranthene & 0.015 \\
\hline ZND & zinc (dissolved) & 0.5 & BBK & benzo(k)fluoranthene & 0.015 \\
\hline ZNT & zinc (total) & 0.5 & BGHIP & benzo(g,h,i)perylene & 0.001 \\
\hline CDD & cadmium (dissolved) & 0.1 & ICDP & indeno(1,2,3-cd)pyrene & 0.001 \\
\hline CDT & cadmium (total) & 0.1 & GLYPH & glyphosate (N-(phosphonomethyl)glycine) & 100 \\
\hline HGD & mercury (dissolved) & 0.03 & AMPA & aminomethylphosphonic acid & 100 \\
\hline HGT & mercury (total) & 0.03 & TRICL & triclosan (2,4,4'-trichloro-2'-hydroxydiphenyl ether) & 0.05 \\
\hline FED & iron (dissolved) & 5 & BENTZN & bentazone & 100 \\
\hline FET & iron (total) & 5 & BISPA & bisphenol-A & 0.05 \\
\hline ALD & aluminium (dissolved) & 4 & MCPP & mecoprop & 10 \\
\hline ALT & aluminium (total) & 4 & EDTA & EDTA & 50 \\
\hline ALR & aluminium (reactive) & 4 & IBPF & ibuprofen & 0.01 \\
\hline AGD & silver (dissolved) & 0.5 & PRPL & propranolol & 0.01 \\
\hline AGT & silver (total) & 0.5 & ERMY & erythromycin & 0.01 \\
\hline DEHP & diethylhexylphthalate & 1 & OFLX & ofloxacin & 0.01 \\
\hline BDE28 & 2,4,4'-tribromodiphenyl ether (PBDE28) & 0.0005 & OXTCY & oxytetracycline & 0.01 \\
\hline BDE47 & 2,2',4,4'-tetrabromodiphenyl ether (PBDE47) & 0.0005 & SLCYA & salicylic Acid & 0.01 \\
\hline BDE99 & 2,2',4,4',5-pentabromodiphenyl ether (PBDE99) & 0.0005 & FLXT & fluoxetine & 0.01 \\
\hline BDE100 & 2,2',4,4',6-pentabromodiphenyl ether (PBDE100) & 0.0005 & E1 & estrone & 0.001 \\
\hline BDE153 & 2,2',4,4',5,5'-hexabromodiphenyl ether (PBDE153) & 0.0005 & E2 & $17 \beta$ estradiol & 0.003 \\
\hline BDE154 & 2,2',4,4',5,6'-hexabromodiphenyl ether (PBDE154) & 0.0005 & EE2 & 17a ethinylestradiol & 0.0003 \\
\hline NOP & Nonylphenol 4-nonylphenol & 0.3 & NOP1ET & nonylphenol ethoxylates (1) & 0.1 \\
\hline TBT & Tributyltin compounds (Tributyltin-cation) & 0.0002 & NOP2ET & nonylphenol ethoxylates (2) & 0.1 \\
\hline & & & NOP3ET & Nonylphenol ethoxylates (3) & 0.1 \\
\hline
\end{tabular}

proposals on EQSs, amending Directives 2000/60/EC as regards priority substances in the field of water policy were made by the European Commission (EC, 2012), and therefore the data reported here are considered in light of these proposals. Table 1 also identifies all chemicals and their abbreviation codes used in summary figures in the supplementary information. Comparable groups of determinands were studied by Hope et al (2012) and Martin Ruel et al. (2012). 
In developing the CIP, consideration was given to establishing the required characteristics for analytical performance. The LOD, precision and bias were defined on the basis of achieving adequate precision at or near the detection limit of interest. These required LODs were set for determinations made in wastewater final effluent to be at least as low as the EQS or other limit value of likely interest such as a predicted no effect value (PNEC). A notional limit for analytical error was agreed for organic chemicals of $\pm 50 \%$ ( $25 \%$ random error, $25 \%$ systematic error) and $\pm 20 \%$ for metals ( $10 \%$ random, $10 \%$ systematic) or the required LOD, whichever was larger. Accredited analytical laboratories were required to submit performance test information to demonstrate that they met the analytical performance targets.

Participating laboratories, contracted by the water companies responsible for delivery of the investigations were required to submit performance test information to substantiate their claim to meet the analytical performance targets. A programme of interlaboratory proficiency tests was also set up with a commercial provider of such services. The tests relied on a combination of routine proficiency tests provided as part of the ongoing proficiency testing programme (Aquacheck, Bury, UK). With respect to data analysis, no statistical outliers were rejected, although approximately 20-30 highly discrepant results out of a total of over 200,000 were queried and rejected from the dataset. Results reported as less than the limit of detection were substituted with a value $1 / 2$ the reporting limit as specified in by EU reporting regulations (EC, 2009). The coherence of the data set and absence of substantial interlaboratory and marked inter-regional effects adds weight to the evidence that bias in procedures of sampling and analysis does not significantly affect the primary interpretation of the data with respect to prioritisation of substances.

\subsection{Data analysis}

The annual average values for each chemical at each WwTWs sampled are presented in the results tables as percentiles which provide a breakdown of the reported concentrations across all of the WwTWs. The concentrations reported represent the percentage of WwTWs where the average concentration measured was at or below the figure presented. For example, for dissolved $\mathrm{Ni}, 50 \%$ of WwTWs returned an average concentration in their effluent of greater than $4.3 \mu \mathrm{g} / \mathrm{L}$ (Table 2).

Percentile values underlined represent a concentration greater than either an EQS or PNEC value.

\section{Results}

\subsection{Works compliance with sanitary and nutrient consents}

The results of the programme are summarised in the supplementary Information in the form of box and whisker diagrams showing results for al WwTWs for each of 40 regulated substances.

Throughout the sampling period all the works were operating within expected design parameters and were compliant against sanitary determinand consents for biochemical oxygen demand (BOD) and suspended solids (SS), with $95 \%$ of the works compliant with the traditional $20 \mathrm{mg} / \mathrm{L}$ and $30 \mathrm{mg} / \mathrm{L}$ permits for BOD and SS respectively. 


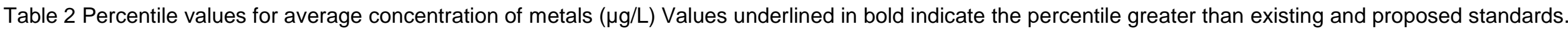

\begin{tabular}{|c|c|c|c|c|c|c|c|c|c|c|}
\hline \multirow[b]{2}{*}{ Substance } & & \multicolumn{4}{|c|}{ Percentile $\mu \mathrm{g} / \mathrm{L}$} & \multicolumn{3}{|c|}{$\begin{array}{c}\text { Freshwater EQS } \\
\mu \mathrm{g} / \mathrm{L}\end{array}$} & \multirow[t]{2}{*}{$\begin{array}{l}\text { PNEC } \\
\mu \mathrm{g} / \mathrm{L}\end{array}$} & \\
\hline & & 5 & 50 & 90 & 95 & 97.5 & AA & MAC & & \\
\hline \multirow[t]{3}{*}{ Aluminium } & Total & 20 & 68 & 246 & 369 & 604 & & & & \\
\hline & Dissolved & 4 & 20 & 54 & 76 & 122 & & & & \\
\hline & Reactive & 2 & 7 & 17 & 21 & 27 & & & 50 & Environment Agency proposed \\
\hline \multirow[t]{2}{*}{ Iron } & Total & 33 & 170 & 694 & 1040 & 1249 & & & & \\
\hline & Dissolved & 14 & 59 & 185 & 238 & 310 & & & 1000 & Defra Direction 2010* \\
\hline \multirow[t]{2}{*}{ Cadmium ${ }^{\text {PHS }}$} & Total & 0.016 & 0.050 & $\underline{0.200}$ & $\underline{0.251}$ & $\underline{0.352}$ & $\leq 0.08^{a}$ & $\leq 0.45^{\mathrm{a}}$ & & \\
\hline & Dissolved & & 0.024 & 0.118 & 0.185 & 0.275 & & & & \\
\hline \multirow[t]{2}{*}{ Chromium } & Total & 0.5 & 0.7 & 3.1 & 5.4 & 7.8 & & & & \\
\hline & Dissolved & 0.5 & 0.6 & 1.9 & 2.1 & 2.1 & & & 3.4 & "BLM adjusted PNEC" \\
\hline \multirow[t]{2}{*}{ Copper } & Total & 3 & 8.3 & 21 & 28 & 31 & & & & \\
\hline & Dissolved & 1.7 & 5.6 & $\underline{15}$ & $\underline{19}$ & $\underline{24}$ & & & 11 & "BLM adjusted PNEC" \\
\hline \multirow[t]{2}{*}{ Lead $^{\text {PS }}$} & Total & 0.2 & 0.8 & 2.1 & $\overline{2.5}$ & 2.9 & & & & \\
\hline & Dissolved & 0.1 & 0.4 & 1.1 & 1.5 & 2 & $1.2^{\mathrm{b}}$ & $14^{\mathrm{b}}$ & 6 & "BLM adjusted PNEC" \\
\hline \multirow[t]{2}{*}{ Mercury ${ }^{\text {PHS }}$} & Total & 0.013 & 0.016 & 0.082 & $0 . \overline{0.109}$ & $0 . \overline{2} 00$ & & & & \\
\hline & Dissolved & & 0.011 & 0.040 & 0.058 & $\underline{0.080}$ & & 0.070 & & \\
\hline \multirow[t]{2}{*}{ Nickel $^{\text {PS }}$} & Total & 1.7 & 4.9 & 9.2 & 14 & 18 & & & & \\
\hline & Dissolved & 1.6 & 4.3 & $\underline{9.3}$ & $\underline{12}$ & $\underline{14}$ & $4^{b}$ & $34^{b}$ & 6 & "BLM adjusted PNEC" \\
\hline Silver & $\begin{array}{l}\text { Total } \\
\text { Dissolved }\end{array}$ & \multicolumn{5}{|c|}{$\begin{array}{l}\text { all results }<0.5 \mu \mathrm{g} / \mathrm{l} \\
\text { all results }<0.5 \mu \mathrm{g} /\end{array}$} & & & & \\
\hline \multirow[t]{2}{*}{ Zinc } & Total & 13.6 & 30.9 & 57 & 69.1 & 83.4 & & & & \\
\hline & Dissolved & 9.9 & 24 & $\underline{48}$ & 59 & 69 & & & 17 & "BLM adjusted PNEC" \\
\hline
\end{tabular}

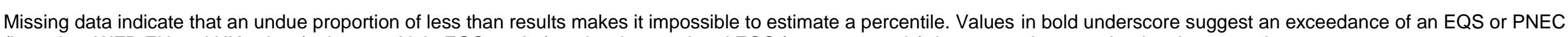
(based on WFD EU and UK values) where multiple EQS apply (e.g. hardness related EQS for some metals) the most stringent value has been used

AA annual average, MAC maximum admissible concentration

PHS Priority hazardous substance

PS Priority substance

a Hardness based, these are lowest for $<40 \mathrm{mg} \mathrm{CaCO}_{3} / \mathrm{L}$

b Based on a bioavailable fraction

http://archive. defra.gov.uk/environment/quality/water/wfd/documents/2010directions.pdf

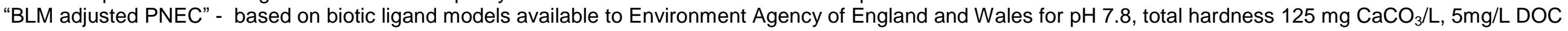




\subsection{Residual final effluent concentrations and their relevance to EQSs}

Summary results for metals are given in Table 2, along with the relevant EQSs. Samples were analysed for both total and dissolved metals; the dissolved fraction is of direct concern for compliance with EQS values specified for receiving waters (for aluminium, the reactive form (Gardner et al, 2008) is relevant to current discussion of standards in the UK). The quantity of metal associated with suspended solids is of concern as insoluble metal bound to solids can accumulate in sediments. In addition, there is also the possibility that metals might re-partition into the dissolved phase. This emphasises the need to maintain good removal of SS in WwTWs to reduce metal loads being discharged. It is apparent that concentrations of $\mathrm{Al}, \mathrm{Fe}, \mathrm{Cr}, \mathrm{Hg}$ and $\mathrm{Ag}$ in the effluents were in all cases below the proposed or existing EQS or PNEC values. The metals for which concentrations were observed to be above the standards were $\mathrm{Cd}, \mathrm{Cu}, \mathrm{Ni}, \mathrm{Pb}$ and $\mathrm{Zn}$.

In the case of the four metals, $\mathrm{Cu}, \mathrm{Ni}, \mathrm{Pb}$ and $\mathrm{Zn}$, the UK will be employing bioavailability-based EQS values (Comber et al., 2008) incorporating DOC correction for Pb or the Biotic Ligand Model (BLM) for $\mathrm{Cu}, \mathrm{Ni}$ and $\mathrm{Zn}$ (DeSchamphelaere and Janssen, 2004), which will be used to determine compliance with standards on a site-specific basis. In Table 2, alongside the relevant standards, a "BLM adjusted PNEC" has also been derived based on biotic ligand models available to the Environment Agency of England and Wales (EA) for waters with a pH 7.8, total hardness $125 \mathrm{mg} \mathrm{CaCO}_{3} / \mathrm{L}$ and $5 \mathrm{mg} / \mathrm{L}$ dissolved organic carbon (DOC). These illustrative EQS values have been selected based on a relatively worst case scenario of water with low concentrations of DOC. The final effluent characteristics of relevance to the BLM are shown in Table 3.

Table 3 Percentile values for average concentration of metals ( $\mathrm{mg} / \mathrm{L})$

\begin{tabular}{|c|c|c|c|c|}
\hline \multirow[b]{2}{*}{ Substance } & \multicolumn{4}{|c|}{ Percentile $\mathbf{~ M g / L}$} \\
\hline & 5 & 50 & 95 & 97.5 \\
\hline Total Suspended solids & 3.8 & 9.8 & 26 & 31 \\
\hline Ammonia (NH4+) & 0.06 & 1.02 & 18.41 & 32.03 \\
\hline Total oxididised nitrogen & 9.8 & 82 & 152 & 160 \\
\hline Biochemical oxygen demand & 0.9 & 4.2 & 19 & 25 \\
\hline Chemical oxygen demand & 20.5 & 42.2 & 87.2 & 100.2 \\
\hline Total phosphorus & & 2.9 & 9.8 & 11.7 \\
\hline Soluble reactive phosphate & 0.81 & 5.5 & 19 & 19 \\
\hline
\end{tabular}

Parameters required for application of biotic ligand models

Percentile $\mathrm{mg} / \mathrm{L}$

\begin{tabular}{lcccc} 
Substance & $\mathbf{5}$ & $\mathbf{5 0}$ & $\mathbf{9 5}$ & $\mathbf{9 7 . 5}$ \\
\hline Sodium & 53 & 79 & 188 & 235 \\
Potassium & 9.2 & 18 & 27 & 34 \\
Magnesium & 4.5 & 8.8 & 25 & 30 \\
Calcium & 37 & 79 & 138 & 141 \\
Total organic carbon & 6.1 & 12 & 28 & 32 \\
Dissolved organic carbon & 3.7 & 9.4 & 24 & 29 \\
Sulphate & 35 & 87 & 168 & 185 \\
Chloride & 64 & 100 & 272 & 342 \\
pH & 6.9 & 7.5 & 8.0 & 8.1 \\
\hline
\end{tabular}


Making these assumptions for the derivation of the BLM adjusted PNEC it can be seen that for dissolved $\mathrm{Pb}$, average concentrations in effluents from all of the WwTWs were below the BLM adjusted PNEC, indicating that using the BLM will result in compliance. However, dilution will be required for $\mathrm{Cu}$ and $\mathrm{Ni}$ to meet the BLM adjusted PNEC at 10\% of sites. For dissolved $\mathrm{Zn}$ concentrations a greater degree of dilution will be required at a higher proportion (50\%) of sites, and the extent of this is currently the subject of further investigation because bioavailability will vary according to conditions downstream after mixing, rather than simply on the basis of its form in effluent. As already highlighted the metals for which concentrations occurred above the EQS were $\mathrm{Cd}, \mathrm{Cu}, \mathrm{Ni}, \mathrm{Pb}$ and $\mathrm{Zn}$. When the BLM adjusted PNECs are applied control measures or dilution will be required for $\mathrm{Zn}$ in $50 \%$ of the works and for $\mathrm{Cd}, \mathrm{Cu}$ and $\mathrm{Ni}$ in $10 \%$ of the works.

\subsection{Concentrations of regulated and emerging organic chemicals in final effluents}

The data for the organic chemicals in the final effluents of the WwTW were compared with existing and proposed EQS (Table 4). Where concentrations in final effluents exceeded existing or proposed standards, there will need to be dilution in receiving waters or treatment at the works to ensure that rivers comply with the relevant standards. In comparison with data for metals in Table 2, it is apparent from Table 4 that many more organic chemicals in the effluents exceed EQS or PNEC standards. Indeed, over $50 \%$ of WwTWs will be currently be reliant on dilution to limit their impact on the receiving waters. However, in the case of the herbicides bentazone, glyphosate (along with its metabolite aminomethyl phosphonic acid - AMPA) and mecoprop the final effluent concentrations at over $50 \%$ of the sites were an order of magnitude below any EQS or PNEC. For glyphosate and AMPA, the highest reported values were only observed at a limited number (around 5\%) of WwTWs. This might be taken to show that in general, there are limited inputs of agricultural herbicides to the sewer system, and it may be that the higher values for glyphosate are related to their domestic urban use and subsequent runoff which does enter the sewer system following rainfall events.

Concentrations of anthracene and naphthalene, for which proposed EQSs are not as stringent as other PAHs, appear not to be of concern with regard to impact on the quality of receiving waters. However, in relation to the EQS proposed in January 2012 (EC, 2012), and listed in Table 4, the final effluent concentrations at over $50 \%$ of WwTWs are of concern for fluoranthene, benzo(a)pyrene, benzo(b)fluoranthene, benzo(k)fluoranthene and at $90 \%$ of WwTWs for benzo(g,h,i)perylene and indeno(1,2,3-cd)pyrene. These 2012 proposed EQSs focus on biota but include implied water quality standards. They are significantly more stringent than were listed in the 2008 EC document (L348/84 $E C, 2008)$, which ranged from $0.002 \mu \mathrm{g} / \mathrm{L}$ for the sum of benzo(g,h,i)perylene and indeno(1,2,3cd)pyrene, up to $0.05 \mu \mathrm{g} / \mathrm{L}$ for benzo(a)pyrene. If concentrations of PAHs in receiving waters are going to comply with the proposed EQS value, it is likely that dilutions in receiving waters may need to be between ten and one hundredfold. 
Table 4 Percentile values for average concentration of organic substances $(\mu \mathrm{g} / \mathrm{L})$ Values underlined in bold indicate the percentile greater than existing and proposed standards.

Percentile $\mu \mathrm{g} / \mathrm{L}$

Freshwater EQS $\mu \mathrm{g} / \mathrm{L} \quad$ PNEC $\quad \mu \mathrm{g} / \mathrm{L}$

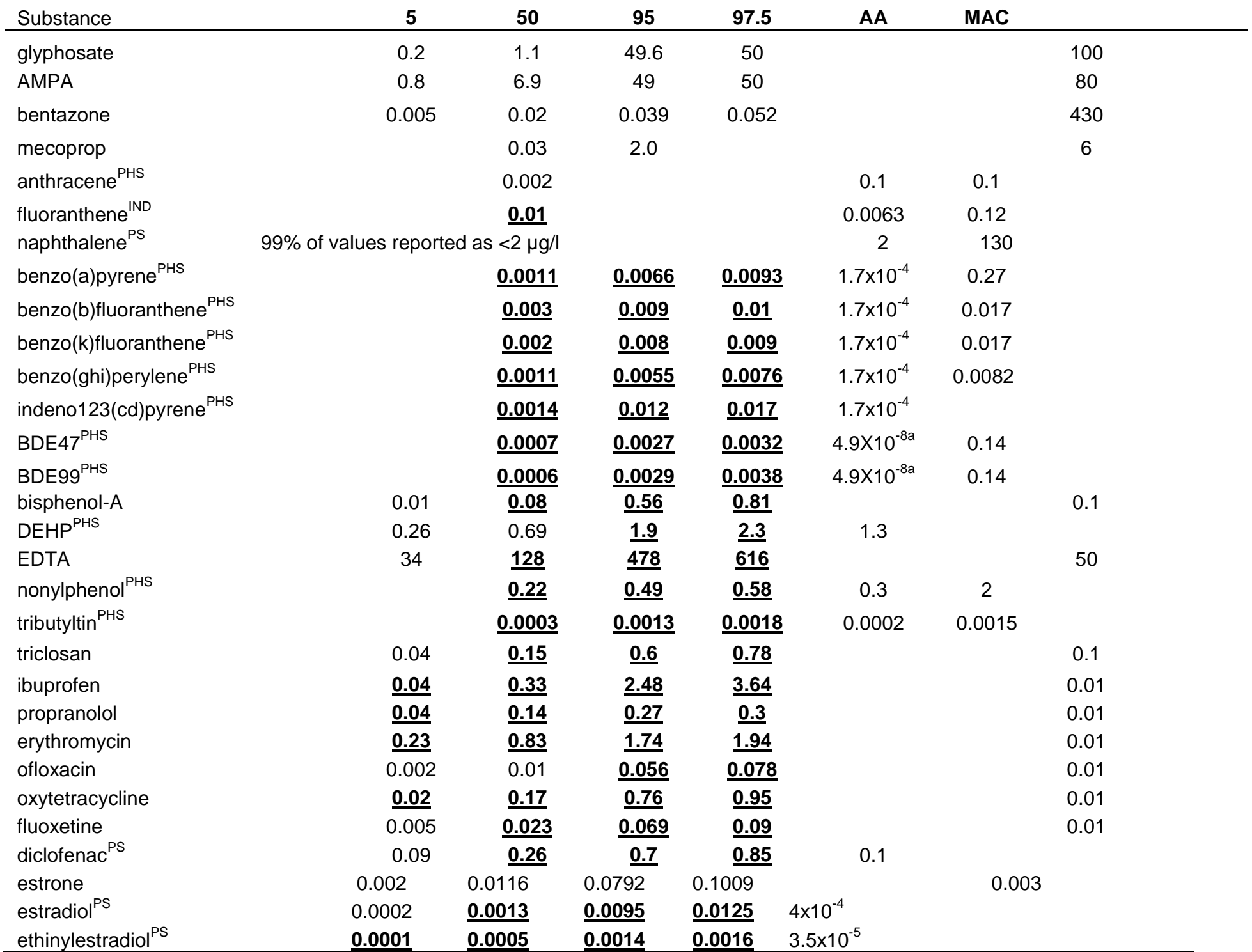

Missing data indicate that an undue proportion of less than results makes it impossible to estimate a percentile. PHS Priority hazardous substance. PS Priority substance. Ind on the EC list as an Indicator of other, more dangerous PAH a The sum of congeners 28, 47, 99, 100, 153 and 154 . PNECs are in many cases notional values based on

recommendation of the Environment Agency of England and Wales 
For the BDEs, the majority of results for BDE28, 100, 153 and 154 were predominantly $<0.0005 \mu \mathrm{g} / \mathrm{L}$, for congeners BDE47 and BDE99 concentrations were frequently detected above this value. The BDEs 100, 153 and 154 are relatively minor components of commercial penta BDE formulations and therefore it is not surprisingly that they were detected at lower concentrations and frequencies compared with BDE 47 and 99 which represent $40 \%$ and $50 \%$ of the commercial product composition, respectively. Considering the present WFD EQSs for BDEs of $0.0005 \mu \mathrm{g} / \mathrm{L}$ for the sum of six BDE congeners $(28,47,99,100,153,154)$, concentrations in effluents exceeded this in $50 \%$ of cases and an approximate 10 times dilution would be required to meet the EQS downstream. However, the 2012 proposed limits for BDEs by the European Commission (EC. 2012) now imply an annual average water EQS of $4.9 \times 10^{-8} \mathrm{\mu g} / \mathrm{L}$ (again the principal focus is on biota), which is four orders of magnitude lower. This means that no surface waters in the UK receiving effluent would be likely to comply, as required dilutions would need to be in the order of 1:10,000 or greater.

For the purposes of classifying the compounds determined in the CIP programme into clear groups, it is worthwhile considering bisphenol-A, DEHP, EDTA, nonylphenol, tributyltin, and triclosan as a set of compounds that will come from domestic and possibly urban / industrial activities. Looking at the national picture, Table 4 indicates that in around $10 \%$ of WwTWs, DEHP may be of concern, with concentrations up to twice that of the standard required in receiving waters. For bisphenol $\mathrm{A}$ and EDTA, the percentages of works discharging at greater than the EQS were $40 \%$ and $80 \%$, respectively; with a maximum dilution required to meet the EQS of 12 and 17 times. This therefore suggests that compliance may be of concern for some WwTWs where only low dilution is available. For triclosan, which has been proposed as a new Specific Pollutant with an EQS value of $0.1 \mu \mathrm{g} / \mathrm{L}$ in Australia (NICNAS, 2012), $60 \%$ of UK WwTWs will require a dilution of up to 10 times to ensure compliance.

In relation to estimated compliance risk at $50 \%$ or more of the WwTWs the chemicals of concern are the high molecular weight PAHs (fluoranthene, benzo(a)pyrene, benzo(b)fluoranthene, benzo(k)fluoranthene, benzo(g,h,i)perylene and indeno(1,2,3-cd)pyrene); the BDEs 47 and 99; TBT and triclosan. The herbicides are not of concern and EDTA, although present, is not regulated.

\section{Implications of the occurrence of pharmaceuticals in final effluents}

For pharmaceuticals, UK PNECs are currently estimated at typically $0.01 \mu \mathrm{g} / \mathrm{L}$ but the 2012 proposals for new EQSs for EE2, E2 and diclofenac involve considerably lower limits (EE2, $\left.3.5 \times 10^{-5} \mathrm{\mu g} / \mathrm{L}\right)(E C$, 2012). In many cases, there will be insufficient dilution available to meet this criterion, leading to a risk of EQS/PNEC exceedance in the receiving water. For example, final effluents from all WwTWs would require significant dilution (1:100 to 1:1000 times) to achieve proposed EE2 limits. For diclofenac and E2 50\% of the final effluents from the WwTWs would require dilution at 10 to 100 times to achieve proposed limits. Currently, there is little available monitoring information for these pharmaceuticals in UK river waters to confirm this assessment. For other substances (erythromycin, oxytetracycline, ibuprofen, ofloxacin, fluoxetine and propanolol, and estrone - E1) there are no current plans for EQS 
to be set at an EU level. However, even in relation to existing estimated PNECs the concentrations of ibuprofen, propranolol, erythromycin and oxytetracycline in the final effluents are above $0.01 \mu \mathrm{g} / \mathrm{L}$ in $95 \%$ of the WwTWs.

In relation to exceedance of EQS or PNEC at $95 \%$ or more of the WwTWs the synthetic hormone and pharmaceutical EE2 is of concern as well as the further pharmaceuticals erythromycin, oxytetracycline, ibuprofen and propranolol. At $50 \%$ of the works fluoxetine and diclofenac are of concern as is the natural steroid estrogen hormone E2. Ofloxacin is not of concern.

\section{Discussion}

\subsection{Correlation analysis}

Correlations (Spearman rank order rho $(\rho)$ correlation, Kendall and Gibbons, 1990) were calculated for all combinations of substances. Having such a large dataset meant that $\rho$ values of greater than 0.23 achieved statistical significance $(p=0.05)$. However, apart from the obvious and established links between substances (eg total and dissolved metal, BOD and COD), there were few practically important associations that might be used accurately to predict the concentrations of one substance from that of another. Such relationships require correlation coefficients approaching 0.9 or greater that were not evident in the data. The use of correlation to explore less predictive associations is also of value in explaining the nature of contaminant behaviour and sources.

In order to be able readily to appreciate the large data array comprising the correlation matrix, software (R development core team, 2008) was employed to produce the visualisation shown in Figure 3. This portrays the associations between different substances as a family tree. It appears there are four main groupings. On the far left of the diagram are substances that have little relationship with the rest of the substances, or indeed with sewage or sewage treatment - calcium, $\mathrm{pH}$, sodium, chloride, potassium and sulphate as well as nickel which is largely unaffected by the treatment process. Moving right, the next grouping includes the main sanitary parameters and the substances that tend to be associated with them. Such association is defined as a tendency to follow to some extent the sanitary parameters such that good effluent quality - eg low BOD and TSS - is associated with low concentrations of ammonia ibuprofen, E1, E2 and, a little more distantly, with low concentrations of TBT triclosan and nonylphenol. These are the trace contaminants for which effluent concentrations might be likely to respond to (ie reduce as a result of) improvements in conventional measures of treatment. The remaining two groups are more or less a miscellany of the remaining 48 substances including metals, pharmaceuticals and other trace organic substances. Particularly interesting is the rightmost group in which the BDEs and PAHs all appear in the same grouping together with DOC and TOC. This is possibly important; it suggests that these substances might be associated with organic carbon, rather than, as might have been expected, with suspended solids. 


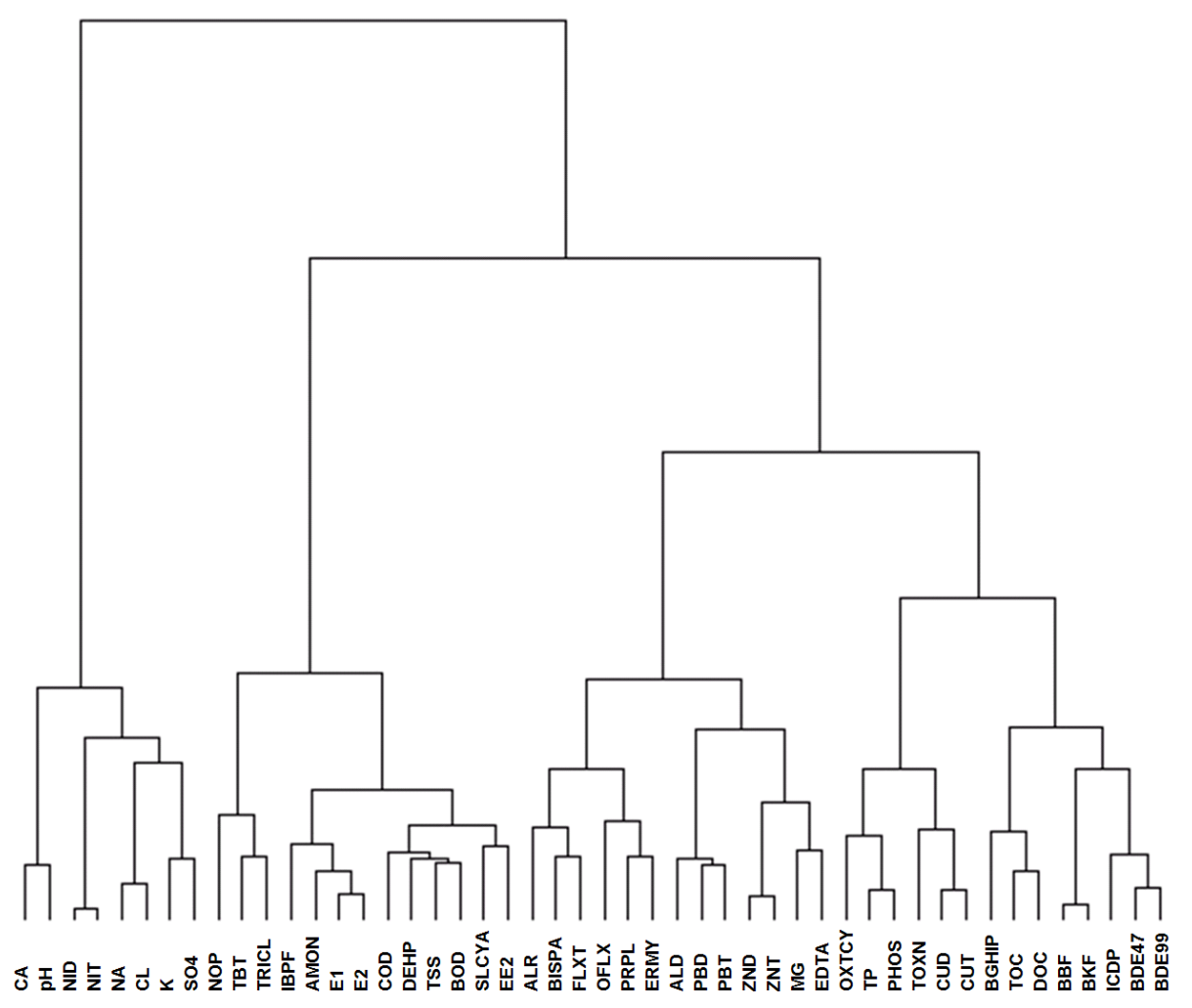

Figure 3 Dendrogram of associations between $\mathrm{C} 1$ substances

4.2 Prioritisation of the chemicals of concern in relation to EQS exceedance at over $50 \%$ of WwTWs

Chemicals have been prioritised for further consideration on the basis of their concentrations in effluent exceeding their EQS or PNEC values in over $50 \%$ of the WwTWs. These were:

1. Metals - $\mathrm{Zn}$

2. PAHs - fluoranthene, benzo(a)pyrene, benzo(b)fluoranthene, benzo(k)fluoranthene, benzo(g,h,i)perylene and indeno(1,2,3-cd)pyrene)

3. BDEs - 47 and 99

4. Organics - TBT

5. Emerging contaminants - triclosan

6. Pharmaceuticals - erythromycin, oxytetracycline, ibuprofen, propranolol, fluoxetine and diclofenac

7. Steroids - EE2, E2.

It is stressed that this prioritisation is generic accounts only for the extent to which different substances were found to be present at over $50 \%$ of the WwTWs effluents in relation to current or proposed limit values; local issues will need to be considered separately. 
In comparison with other countries where recent national/regional surveys have been completed (Hope et al. 2012; Martin Ruel et al. 2012) common hazardous chemicals of concern are: PAHs, BDEs, TBT, emerging chemicals such as triclosan and pharmaceuticals such as diclofenac. Martin Ruel et al. (2012) prioritised their chemicals based on dividing the final effluent concentration by the EQS. Values $>1$ at a frequency of $>70 \%$ were classed as high frequency chemicals of concern. This is similar to this study where values $>1$ at a frequency of $>50 \%$ were applied. In contrast, Hope et al. (2012) in the US focussed more on persistent organic pollutants. Chemicals in common with this study and that of Martin Ruel et al (2012) were the BDEs 47 and 99. In terms of the PAHs comparable concentrations with those in the US were observed in the region of $0.01 \mu \mathrm{g} / \mathrm{L}$. However, proposed EU standards of $1.7 \times 10^{-4} \mathrm{\mu g} / \mathrm{L}$ are more stringent than the US planned initiation level (PIL) applied by Hope et al. (2012) of $0.02-0.5 \mu \mathrm{g} / \mathrm{L}$. Therefore the occurrence of PAHs was prioritised in the EU studies but not by the US study (Hope et al. 2012). The metals of concern detected in the final effluents in France, at frequencies of $>70 \%$, were $\mathrm{Ni}, \mathrm{Pb}, \mathrm{Cd}, \mathrm{Hg}$. In this UK study these metals were not observed at concentrations above the EQSs at those frequencies.

The chemicals occurring widely in final effluents throughout the UK, frequently above standards, provide a focus for control measures that may need to be applied at a large number of locations. An initial expectation may be that dilution of effluents in receiving waters will mean that exceedances of EQS or PNEC values are limited. Historically, wastewater treatment design has been based on the Royal Commission criteria which afforded a minimum dilution of 1:8 between the final effluent and river water (Royal Commission 1898-1914). This dilution is now commonly interpreted as $1: 10$. The availability of a 1:10 dilution would clearly increase the probability of downstream compliance. For example, for Zn, PAHs, triclosan, fluoxetine and EE2 a 1:10 dilution would reduce the number of potential exceedances from $50 \%$ of the WwTWs to below $10 \%$. However, this dilution is not always realistic at all sites. The fact that the "upstream" flow might already contain the contaminants of interest further undermines the principle of reliance on dilution. For the PAHs, benzo(b)fluoranthene, and the pharmaceutical erythromycin a dilution ratio of 1:50 would be required to reduce the number of WwTWs effected (Table 5). Recent estimates have estimated that for 3,704 WwTW for which estimated river flow data was available within $1 \mathrm{~km}$ of the discharge point, that $28 \%$ of the works had a dilution of less than 1:10 compared with measured WwTW flows or consented dry weather flows (Comber et al, 2011).

Dilution requirements for the BDEs are over one hundredfold - many times that available (Table 5). Hence other options for control to ensure compliance with WFD requirements must be considered. For instance, these might involve source control measures, enhanced treatment options or alternative approaches to assessing compliance with standards such as taking into account bioavailability for organic chemicals as currently utilised for metals. In a study by Eriksson et al. (2011) concentrations would only be reduced for chemicals including $\mathrm{Cd}$, hexachlorobenzene (HCB), nonylphenol and BDE by fully implementing restrictions on use as part of an emission control strategy. In addition, the scenarios studied illustrated other opportunities for managing hazardous chemicals before they 
become part of the urban water cycle along with managing historic sinks such as sediments (Eriksson et al. 2011). Source control measures are already widely applied to priority hazardous substances owing to the need for cessation of discharge by 2020. OctaBDE and Penta-BDE (e.g. including BDE47 and BDE99) flame retardants have been banned under the 24th amendment to the marketing and use Directive 76/769/EEC since $15^{\text {th }}$ August 2004. Their presence in wastewaters is therefore a result of residual use as flame retardants in furniture in domestic properties. The breakdown of foams leads to accumulation in materials such as clothes, curtains and fabrics, which when washed leads to an input to sewer. These inputs to sewer would therefore be expected to decrease with time owing to replacement of furniture and degradation. However, like the reductions in concentrations observed for TBT and PCB any decline in concentration is likely to be greater than 30 years and will also still be unlikely to reduce concentrations to below the EQS values in the short to medium term.

Concentrations, however, are only one approach, albeit the principal one used by regulatory authorities, for measuring inputs of hazardous chemicals. There is an increasing focus on the loads of chemicals input to the environment as a means of assessing possible impacts and of understanding the relative significance of sources within catchments (Musoleff et al. 2010). The loads discharged from the WwTWs included in this study are tabulated in the supplementary data. It is noteworthy that loads of hydrophobic, recalcitrant chemicals that are likely to persist in the environment for some time. This emphasises the importance of understanding loads for longer term impacts on the quality of sediments (Yen et al., 2009) and groundwater (Musoleff et al., 2010).

Table 5 the potential dilution required for chemicals which are present in over $50 \%$ of UK WwTWs above the EQSs or PNEC concentrations

\section{Dilution required}

\begin{tabular}{|c|c|c|c|c|}
\hline Substance & $1: 10$ & $1: 50$ & $1: 100$ & $>1: 100$ \\
\hline fluoranthene & Yes & & & \\
\hline benzo(a)pyrene & Yes & & & \\
\hline benzo(b)fluoranthene & & Yes & & \\
\hline benzo(k)fluoranthene & Yes & & & \\
\hline benzo(ghi)perylene & Yes & & & \\
\hline indeno123(cd)pyrene & Yes & & & \\
\hline BDE47 & & & & Yes \\
\hline BDE99 & & & & Yes \\
\hline tributyltin & Yes & & & \\
\hline triclosan & Yes & & & \\
\hline ibuprofen & Yes & & & \\
\hline propranolol & Yes & & & \\
\hline erythromycin & & Yes & & \\
\hline oxytetracycline & Yes & & & \\
\hline diclofenac & Yes & & & \\
\hline estradiol & Yes & & & \\
\hline ethinylestradiol & Yes & & & \\
\hline
\end{tabular}

Reliance on existing available tertiary treatment to meet EQS and reduce loads to the environment is 
also not necessarily advisable as these data indicate a wide range of effluent quality for advanced or tertiary wastewater treatment processes. Hence such processes do not represent a guaranteed solution and could involve disproportionate costs if applied at all works. This emphasises the need for a robust economic evaluation as part of any mitigation strategy (Eriksson et al. 2011; Jones et al. 2007), with careful consideration of the time required for marketing initiatives to take effect.

Nevertheless, concomitant improvements in the removal of hazardous chemicals can be achieved by the optimisation of existing process (McAdam et al. 2010, 2011) and upgrading solutions for nutrient removal and sanitary determinands. For example, the upgrading of Beckton WwTWs in London in the mid 1960's with the introduction of activated sludge treatment to reduce BOD and SS discharges to the River Thames was subsequently found by examination of the sediment record 30 years later to have significantly improved the removal of heavy metals, polychlorinated biphenyls and organochlorine insecticides (O'Reilly-Wiese et al. 1997a,b; Scrimshaw and Lester, 1997). If source control cannot be utilised, for example for certain pharmaceuticals and natural hormones, advanced tertiary wastewater treatment options may be an alternative to achieve compliance. A large number of tertiary / "end of pipe" treatment options are available. However, some of these processes, notably advanced oxidation or membrane filtration can be costly and may result in increased chemical use (Jones et al. 2007).

Further data from this ongoing programme will explore topics including process performance and contaminant sources.

\section{Conclusions}

1. This extensive monitoring programme has demonstrated that trace contaminant concentrations in wastewater treatment works' effluents can exceed existing or proposed EQS values. In over $50 \%$ of the WwTWs monitored, effluent concentrations of the following substances exceed the relevant EQS Zn, PAHs - fluoranthene, benzo(a)pyrene, benzo(b)fluoranthene, benzo(k)fluoranthene, benzo(g,h,i)perylene and indeno(1,2,3cd)pyrene), BDEs - 47 and 99, TBT, triclosan, erythromycin, oxytetracycline, ibuprofen, propranolol, fluoxetine, diclofenac and EE2 and E2.

2. A nominal tenfold dilution in the receiving water will ensure compliance with EQSs for the majority hazardous chemicals, apart from the BDEs and to a lesser extent the steroids and (when / if regulated) some pharmaceuticals.

3. In some cases there will be insufficient dilution to guarantee compliance with downstream EQSs. Here additional management options will have to be considered, taking account of the need for proportionality between costs and benefits. Measures to be considered will include: source control, substance substitution, tertiary treatment, and optimisation of existing processes. 
Acknowledgement - The authors wish to thank the co-ordinator of the CIP programme - UK Water Industry Research (UKWIR) for authorising the use of the information reported here, and the UK Water Utility companies Anglian, Dwr Cymru, Northumbrian, Scottish, Severn Trent, Southern, South West, Thames, United Utilities, Wessex and Yorkshire Water for their considerable efforts in generating it.

\section{References}

Aquacheck Bury UK http://www.Igcpt.com/productviewnarrow.aspx?SchemelD=77

Bedding ND, Mclntyre AE, Perry R and Lester JN. Organic contaminants in the aquatic environment. I. sources and occurrence. Sci. Total Environ., 1982, 25, 143-167.

Bedding ND, McIntyre AE, Perry R and Lester JN. Organic contaminants in the aquatic environment. II. behaviour and fate in the hydrological cycle. Sci. Total Environ., 1983, 26, 255-312.

Behera SK, Kim HW, Oh J-E, Park H-S. Occurrence and removal of antibiotics, hormones and several other pharmaceuticals in wastewater treatment plants of the largest industrial city of Korea. Science of the Total Environment 2011; 409, 4351-4360.

Buisson RSK, Kirk PWW and Lester JN. Determination of chlorinated phenols in water, wastewater and wastewater sludge. Chromatogr. Sci., 1984, 22, 339-342.

Comber SDW, Merrington G, Sturdy L, Delbeke K and van Assche F. Copper and zinc water quality standards under the EU Water Framework Directive: The use of a tiered approach to estimate levels of failure. The Science of the Total Environment 2008; 403, 12-22.

Comber S, Daldorph P, Delaney P, Gardner M, Murrell K, Smith R and Constantino, C. Chemical source apportionment under the WFD. Final Report for UK Water Industry Research (UKWIR), 1 Queen Anne's Gate, London, UK, 2011..

De Schamphelaere KAC, Janssen CR. Development and field validation of a BLM predicting chronic copper toxicity to Daphnia magna. Environ Toxicol Chem 2004;23:1365-75.

Dodds EC, Goldberg L, Lawson W and Robinson R Oestrogenic activity of certain synthetic compounds. Nature; 1938, 141, 247.

EC European Commission (2000). Directive 2000/60/EC of the European Parliament and of the Council of 23 October 2000 establishing a framework for Community action in the field of water policy. Accessed 23/05/2012 at http://eur-

lex.europa.eu/LexUriServ/LexUriServ.do?uri=CELEX:32000L0060:EN:NOT

EC European Commission (2008). Priority Substances Daughter Directive - Directive 2008/105/EC of the European Parliament and of the Council of 16 December 2008 on environmental quality standards in the field of water policy Accessed 23/05/2012 at http://eur-lex.europa.eu/LexUriServ/LexUriServ.do?uri=OJ:L:2008:348:0084:0097:EN:PDF

EC European Commission (2009). Council of European Communities, 'QA/QC directive' technical specifications for chemical analysis and monitoring of water status. Commission Directive 2009/90/EC of 31 July 2009

EC European Commission (2012). Proposal for a Directive of the European Parliament and of the Council amending Directives 2000/60/EC and 2008/105/EC as regards priority substances in the field of water policy Brussels, 31.1.2012 COM(2011) 876 final 2011/0429 (COD)

http://ec.europa.eu/environment/water/water-dangersub/pdf/com_2011_876.pdf 
Eriksson E, Revitt DM, Ledin A, Lundy L, Lützhøft H, Wickman T, Mikkelsen PS. Water management in cities of the future using emission control strategies for priority hazardous substances. Water Science and Technology 2011, 64(10), 2109-2117.

Feldman., C., Preservation of dilute mercury solutions. Anal. Chem., (1974). 46 (1), pp 99-102.

Gabriel O, Ruzicka K, Kreuzinger N. Upgrading Vienna's wastewater treatment plant - linking point source emissions to Environmental Quality standards. Water Science and Technology 2012; 65(7), 1290-1297.

Gardner, M.J., Brown, B., Whitehouse, P. and Birch, M. Towards the Establishment of an Environmental Quality Standard for Aluminium in Surface Waters. Journal of Environmental Monitoring, (2008), 10, 877-882.

Gardner MJ, Comber SDW, Leverett D and Gravell A. Sample Stability of Trace Priority Substances in Wastewater, Anal. Lett. 2012; in press, DOI 10.1080/00032719.2012.677789

González S, López-Roldán R, Cortina J-L. Presence and biological effects of emerging contaminants in Llobregat River basin: A review. Environmental Pollution 2012;161, 83-92.

Hope BK, Pillsbury L, Boling B. A state-wide survey in Oregan (USA) of trace metals and organic chemicals in municipal effluent. Science of the Total Environment 2012;417-418, 263-272.

Koh YKK, Lester JN and Scrimshaw MD. The Fate and Behaviour of Alkylphenols and their Polyethoxylates in an Activated Sludge Plant. Bull. Environ. Contam. Toxicol., 2005, 75, 1098-1106.

Kolpin DW, Furlong ET, Meyer MT, Thurman EM, Zaugg SD, Barber LB Pharmaceuticals, hormones, and other organic wastewater contaminants in U.S. streams, 1999-2000: a national reconnaissance. Environmental Science and Technology 2002; 36(5), 1202-1211.

Lester JN. Significance and behaviour of heavy metals in waste water treatment processes. I. sewage treatment and effluent discharge. Sci. Total Environ.; 1983, 30, 1-44.

Lester JN, Sterritt RM and Kirk PWW. Significance and behaviour of heavy metals in waste water treatment processes. II. sludge treatment and disposal. Sci. Total Environ.; 1983, 30, 45-83.

Martínez Bueno MJ, Gomez MJ, Herrera S, Hernando MD and Agüera A. Occurrence and persistence of organic emerging contaminants and priority pollutants in five sewage treatment plants of Spain: Two year pilot survey monitoring. Environmental Pollution 2012; 164, 267-273.

Martin Ruel M, Choubert J-M, Budzinski H, Miége C, Esperanza M and Coquery M. Occurrence and fate of relevant substances in wastewater treatment plants regarding Water Framework Directive and future legislations. Water Science and Technology 2012; 65(7), 1179-1189.

Musoleff A, Leschik S, Reinstorf F, Strauch G, Schirmer M. Micropollutant loads in the urban water cycle. Environmental Science and Technology 2010, 44, 4877-4883.

NICNAS (2012) Priority Existing Chemical Assessment Report No. 30 Triclosan January 2009 NATIONAL Industrial Chemicals Notification and Assessment Scheme GPO Box 58, Sydney NSW 2001, Australia www.nicnas.gov.au. http://www.nicnas.gov.au/publications/car/pec/pec30/pec 30 full report pdf.pdf accessed $\underline{14 / 04 / 2012}$

R Development Core Team (2008). R: A language and environment for statistical computing. $R$ Foundation for Statistical Computing, Vienna, Austria. ISBN 3-900051-07-0, URL http://www.Rproject.org.

Robertson AM and Lester JN Supercritical fluid extraction of s-triazines and phenylurea herbicides from sediment. Environ. Sci. and Technol. 1994; 28, 346-351. 
Rodil R, Quintana JB, Concha-Graňa E, López-Mahía P, Muniategui-Lorenzo S, Prada-Rodríguez D. Emerging pollutants in sewage, surface and drinking water in Galicia (NW Spain). Chemosphere 2012; 86, 1040-1049.

Soares A, Guieysse B, Jefferson B, Cartmell E and Lester JL.Nonylphenol in the environment: A critical review on occurrence, fate, toxicity and treatment in wastewaters. Environment International 2008; 34(7), 1033-1049.

Sumpter J. Protecting aquatic organisms from chemicals: the harsh realities. Philosophical Transactions of the Royal Society 2009; 367, 3877-3894.

Yen JH, Liao WC, Chen, WC Wang, YS. Interaction of polybrominated diphenyl ethers (PBDEs) with anaerobic mixed bacterial cultures isolated from river sediment. Journal of Hazardous Materials 2009, $165,518-524$. 